Tersedia online di: http://ejournal-balitbang.kkp.go.id/index.php/JP
e-mail:jurnalpari@gmail.com
JURNAL PARI
Volume 6 Nomor 2 Desember 2020
p-ISSN: 2502-0730
e-ISSN : 2549-0133

\title{
RESIKO IMPLEMENTASI CLOUD COMPUTING DAN PENANGANANNYA DALAM MENDUKUNG RISET KELAUTAN DAN PERIKANAN
}

\author{
Eva Mustikasari dan Dani Saepuloh \\ Pusat Riset Kelautan, BRSDMKP, KKP \\ Diterima tanggal : 26 Oktober 2020 Diterima setelah perbaikan : 19 November 2020 \\ disetujui terbit : 22 Desember 2020
}

\begin{abstract}
ABSTRAK
Riset adalah proses mengumpulkan, menganalisis, dan menerjemahkan informasi atau data secara sistematis untuk menambah pemahaman kita terhadap suatu fenomena tertentu yang menarik perhatian kita. FORMAL RESEARCH yaitu riset yang ditujukan untuk menambah pemahaman kita terhadap suatu fenomena dan untuk dikomunikasikan kepada komunitas (dipublikasikan) melalui media internet (online) dengan menggunakan teknologi cloud Computing. Menggunakan Cloud Computing harus diperhatikan keamanan data agar pengguna memiliki kepercayaan dalam menggunakannya. Pengembangan cloud computing akan mengarah pada berkembangnya suatu teknologi pengiring cloud computing yaitu suatu bentuk teknologi yang dapat menjamin keamanan data. Selain itu, perkembangan cloud computing ini selanjutnya akan memasuki tahap integrasi antar berbagai provider dengan mengedepankan prinsip interoperabilitas.
\end{abstract}

\section{Kata Kunci: Riset; implementasi; cloud computing; Perikanan}

\begin{abstract}
Research is the process of collecting, analyzing, and systematically translating information or data to increase our understanding of a particular phenomenon that interests us. FORMAL RESEARCH, which is research aimed at increasing our understanding of a phenomenon and to be communicated to the community (published) via the internet (online) using cloud computing technology. Using Cloud Computing data security must be considered so that users have confidence in using it. The development of cloud computing will lead to the development of a technology that accompanies cloud computing, which is a form of technology that can ensure data security. In addition, the development of cloud computing will then enter the integration stage between various providers by prioritizing the principle of interoperability.
\end{abstract}

\section{Keywords: Research; implementasi; cloud computing; Fishery}

\section{PENDAHULUAN}

Riset adalah proses mengumpulkan, menganalisis, dan menerjemahkan informasi atau data secara sistematis untuk menambah pemahaman kita terhadap suatu fenomena tertentu yang menarik perhatian kita. Sekalipun kegiatan ini dapat saja terjadi untuk hal sehari-hari, tapi kita fokuskan pada FORMAL RESEARCH yaitu riset yang ditujukan untuk menambah pemahaman kita terhadap suatu fenomena dan untuk dikomunikasikan kepada komunitas (dipublikasikan). Hampir semua penelitian/ riset yang berfokus pada formal riset mengunakan komputasi sebagai alat dalam melakukan pengolahan data. Demikian banyak data yang diolah, dan dalam waktu yang cepat informasi hasil pengolahan data sebagai hasil riset harus mampu di publikasikan kepada publik terutama pemangku kepentigan yang menggunakan informasi itu sebagai alat bantu kelangsungan hidup. Informasi yang diperoleh dari hasil penelitian adalah informasi yang dikeluarkan melalui tahapan proses pengolahan data dengan beragam metoda penelitian. Dari mulai metoda sederhana (simple) sampai metoda yang komleks. Kompleksitas dari metoda penelitian umumnya merupakan kendala, yang paling banyak muncul

Korespondensi penulis:

Gedung BRSDM KP II, Lantai V, Jl. Pasir Putih II, Ancol Timur Jakarta Utara, 14430

Tlp. (021) 64700755 ext 3120 / Fax. : (021) 64711654

email : eva.mustikasari@gmail.com / d4n1.saepuloh@gmail.com 
adalah kendala teknis dimana data yang harus diolah banyak, software model terbatas karena membutuhkan biaya yang cukup tinggi untuk menyediakannya, sumberdaya manusia yang sangat terbatas dan banyak lagi kendala teknis dan non teknis yang lain. Penelitian dengan metode yang rumit akan jauh lebih ringan jika dilakukan dengan dukungan infrastruktur yang memadai, teknologi yang mumpuni dan sumberdaya yang handal. Tidak kalah penting lagi adanya implementasi teknologi yang memungkinkan penelitian/riset bisa dilakukan dimana saja, kapan saja tanpa batas ruang dan waktu. Bukan hanya informasi yang mampu diakses secara online. Tetapi penelitian/riset pun harus mampu dilakukan secara online.

Cloud Computing adalah sebuah proses pengolahan daya komputasi melalui jaringan internet yang memiliki fungsi agar dapat menjalankan program melalui komputer yang telah terkoneksi satu sama lain pada waktu yang sama (Alex Budiyanto, 2012).

\section{HASIL DAN PEMBAHASAN Resiko Cloud Computing}

Sebagaimana yang dikatakan sebagai bisnis service, dengan teknologi cloud pengguna (user) sebaiknya mengetahui dan memastikan apa yang dibayar dan apa yang diinvestasikan sepenuhnya memang untuk kebutuhan dalam menggunakan service ini. Merujuk kepada (Robbins, 2009), resiko yang mesti dihadapi user dalam penggunaan cloud computing ini antara lain:

1. service level, artinya kemungkinan service performance yang kurang konsisten dari provider. Inkonsistensi cloud provider ini meliputi, data protection dan data recovery,

2. privacy, yang berarti adanya resiko data userakan diakses oleh orang lain karena histing dilakukan secara bersama-sama,

3. compliance, yang mengacu pada resiko adanya penyimpangan level compliance dari provider terhadap regulasi yang diterapkan oleh user,

4. data ownership mengacu pada resiko kehilangan kepemilikan data begitu data disimpan dalam cloud,

5. data mobility, yang mengacu pada kemungkinan share data antar cloud service dan cara mendapatkan data kembali jika suatu saat user melakukan proses terminasi terhadap layanan cloud computing.

Resiko lain diluar lima poin yang disebutkan diatas dan tidak kalah pentingnya untuk diperhatikan (khususnya di Indonesia dengan tingkat pengangguran tinggi) adalah ancaman terhadap pekerja Teknologi
Industri (TI) konvensional.

Hadirnya cloud computing diprediksi bisa mengancam para tenaga kerja TI di Indonesia, yaitu mereka yang masih bekerja secara konvensional. Cloud Computing bakal mengancam para tenaga kerja TI konvensional (Susanto Djaja, 2010).

Hal ini bukanlah tanpa alasan. Teknologi itu bisa mempersingkat waktu ketika pengguna ingin melakukan perubahan. Sehingga, kehadiran pekerja TI konvensional di lokasi tidak selalu dibutuhkan.

Contoh kasus jika Anda ingin mengganti sofware dari versi 1 ke 2, yang ada di seribu client, di seluruh Indonesia. Kini tidaklah tenaga IT harus pergi ke masing-masing cabang, cukup dengan satu klik diCloud Computing semuanya beres. Meski belum banyak digunakan, layanan Cloud Computing tampaknya mulai menjamur di Indonesia. Beberapa vendor besar pun sudah menyiapkan beberapa produknya, sebut saja Dell, Hewlett-Packard (HP), Cisco atau pun Microsoft.

Siapkah pekerja TI konvensional Indonesia untuk perubahan itu?

\section{Resiko yang Dihadapi Dilembaga Riset}

Cloud computing secara tidak langsung mampu menciptakan implementasi riset secara online. Keuntungan riset menggunakan cloud computing adalah kecepatan dan kepraktisannya. Disamping itu keuntungan lain yang diperoleh diantaranya:

- Data yang masuk akan terekam secara otomatis tanpa kuatir human error akibat salah input manual.

- Secara langsung "memesan" sumber daya yang dibutuhkan, seperti processor time dan kapasitas penyimpanan melalui control panel elektronis yang disediakan. Jadi tidak perlu berinteraksi dengan personil customer service jika perlu menambah atau mengurangi sumberdaya komputasi yang diperlukan.

- Layanan yang tersedia terhubung melalui jaringan pita lebar, terutama untuk dapat diakses secara memadai melalui jaringan internet, baik menggunakan thin client, thick client ataupun media lain seperti smartphone.

- Penyedia layanan cloud, memberikan layanan melalui sumberdaya yang dikelompokkan di satu atau berbagai lokasi data center yang terdiri dari sejumlah server dengan mekanisme multi-tenant. Mekanisme multi-tenant ini memungkinkan sejumlah sumberdaya komputasi tersebut digunakan secara bersama-sama oleh sejumlah user, di mana sumberdaya tersebut baik yang 
berbentuk fisik maupun virtual, dapat dialokasikan secara dinamis untuk kebutuhan pengguna/ pelanggan sesuai permintaan. Efeknya dalam implementasi bidang penelitian salah satunya adalah hasil penelitian dapat diperoleh dalam waktu yang cepat, sehingga user dapat dengan cepat pula mengakses informasi hasil penelitian.

Namun implementasi coud computing di Indonesia sambutannya masih sepi. Sepinya sambutan dunia teknologi informasi dalam negeri terhadap Cloud Computing ini, mungkin disebabkan beberapa faktor, di antaranya:

1. Penetrasi infrastruktur internet yang bisa dibilang masih terbatas, bandwith masih terbatas;

2. Tingkat kematangan pengguna internet, yang masih menjadikan media internet utamanya sebagai media hiburan atau sosialisasi;

3. Tingginya investasi yang dibutuhkan menyediakan layanan cloud ini, karena

harus merupakan kombinasi antara infrastruktur jaringan, hardware dan software sekaligus.

Sehingga saat gelombang besar Cloud Computing ini sampai di sini, tidak hanya pemain asing besar saja yang akan menangguk keuntungan. Tentu saja peran pemerintah sebagai fasilitator dan regulator sangat diperlukan di sini.

Khusus bagi lembaga penelitian, selain faktor resiko tersebut diatas faktor lain yang menjadi ancaman resiko cloud computing ini diantaranya adalah:

- Sangat tergantung pada koneksi internet, tanpa internet berarti tidak bisa kerja padahal lembaga penelitian harus tetap eksis dalam menyampaikan informasi hasil riset ke publik.

- Internet Cloud computing tidak akan pernah bisa digunakan ketika tidak ada akses internet. Pun ketika ada akses, dibutuhkan koneksi yang benarbenar mumpuni (not recommended for "Speed That You Can't Trust" user).

- Aplikasi dan penyimpanan data online sangat tergantung pada pihak ketiga yang berarti bila server mereka sedang "down" berarti tidak bisa kerja/ mengakses situs mereka.

- Kepercayaan, apakah sudah siap untuk mempercayakan data penting perusahaan/ organisasi/lembaga kepada pihak ketiga? Dan mungkin faktor ini yang paling mengkhawatirkan.

- Privacy dan keamanan. Meski umumnya gratis, sebagian besar penyedia cloud computing mengembangkan sistem dengan mekanisme tertutup (propriarti). User tidak pernah tahu bagaimana mekanisme layanan tersebut bekerja di dalam. Dari segi keamanan, ada resiko akun got hacked karena diakses secara ceroboh melalui browser.

- Mau tidak mau para pengembang piranti lunak dipaksa harus membuat aplikasinya mendukung pelaksanaan cloud computing agar tidak ditinggalkan penggunanya.

- Pengguna mau tidak mau belajar aplikasi padanan dari desktop yang terdapat dalam cloud computing.

\section{Antisipasi Resiko Implementasi Cloud Computing}

Antisipasi ancaman (Security Threats) didalam dunia jaringan informasi adalah perlu diidentifikasi acaman terhadap sistem. Identifikasi mencakup:

- Darimana saja ancaman tersebut?

- Dari dalam organisasi (pegawai)?

- Dari luar organisasi (crackers, kompetitor)?

- Sumber: oleh manusia (sengaja, tidak sengaja) atau alam (bencana,musibah)?.

- Tingkat kesulitan.

- Probabilitas ancaman menjadi kenyataan.

Melihat ancaman dan resiko yang terjadi maka perlu adanya pengamanan menyeluruh dan berlapis (Gambar 3) terhadap sistem, dimana melibatkan tiga unsur penting diantaranya:

- People : awareness, skill

- Process: security as part of business process.

- Technology: Implementation.

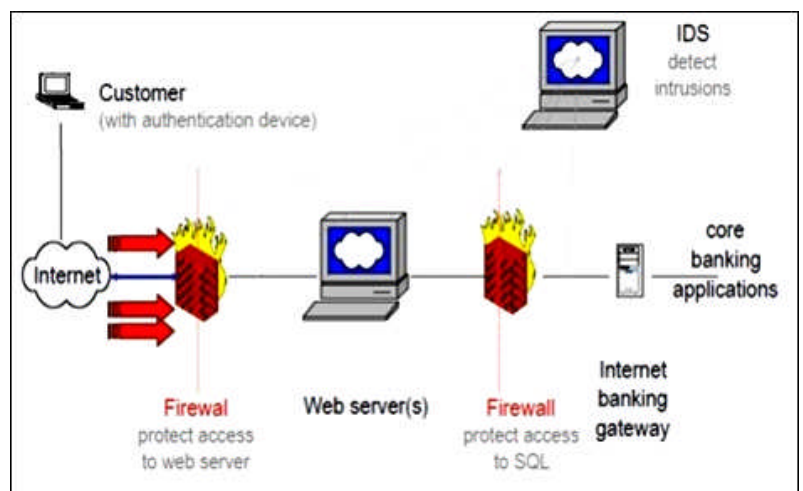

Gambar 3. Sistem pengamana berlapis (sumber: kuliah keamanan informasi, Dr. Budi Rahardjo)

Jika organisasi baru saja mengeksplorasi teknologi cloud ada beberapa cloud service yang sudah cukup mapan dan dapat di pertimbangkan misalnya sebagai e-mail service. Namun untuk masalah scurity, dengan mengembangkan internal infrastruktur organisasi menjadi model cloud akan lebih baik. 
Dengan begini role IT kini ikut berperan dalam hal business model yang dibutuhkan untuk berbagai bidang baik segi industri, ekonomi dan bidang penelitian saat ini. Bagaimana organisasi meningkatkan kecepatan dan uptime? dan bagaimana organisasi dapat mensupport business operation dengan sedikit dan pengeluaran yang fix?

Langkah awal yang harus anda lakukan adalah mempelajari sistem kontrak dari cloud service. pastikan setiap process menjadi simple, dapat berulang ulang dan menjadi nilai tambah untuk bisnis/ kegiatan organisasi.

Kedua, harus mengidentifikasi service apa yang dapat organisasi manfaatkan di dalam cloud dan mana yang seharusnya bersifat internal. Hal ini sangat penting untuk diketahui mengenai system dan service core yang dapat dimanfaatkan oleh bisnis/ kegiatan organisasi. dan sebaiknya organisasi harus mengkategorikan beberapa elemen bisnis/ kegiatannya berdasarkan resiko dari penggunaan cloud service.

Langkah terakhir, harus melakukan strategi sourcing untuk mendapatkan biaya yang sangat murah, namun memiliki scalability dan flexibility untuk kebutuhan bisnis/kegiatan organisasi. Hal ini termasuk pertimbangan akan proteksi data ownership dan mobility, compliance dan beberapa element seperti halnya kontrak IT tradisional. Dan yang juga harus diperhatikan adalah mempunyai backup system jika sewaktu-waktu fungsi system teknologi cloud mengalami gangguan.

Dalam rangka meningkatkan penelitian dan pengembangan menuju era cloud computing di Indonesia, perlu dilakukan langkah-langkah berikut :

- Meningkatkan SDM di bidang cloud computing dengan mengadakan pelatihan, pendidikan, transfer knowledge, sehingga kompetensi SDM sinergis dengan perkembangan yang ada.

- Perlu dibentuknya 3C (Cloud Computing Community) atau Masyarakat Komputasi Awan Indonesia (Maskawan) sebagai salah satu wadah Community on Practices untuk berkolaborasi untuk semua elemen yang terkait.

- Orientasi Community ini antara lain :

a. sharing knowledge,

b. best practices,

c. innovation community yang senantiasa berinovasi, dan tentunya responsif terhadap kebutuhan pasar. Hal ini antara lain dilakukan dengan penelitian dan pengembangan antar komponen yang ada, antara lain dengan joint research.
Dengan demikian diharapkan dengan langkahlangkah tersebut penelitian dan pengembangan di era menuju cloud computing dapat sinergis antara kebutuhan SDM dan perkembangan teknologi yang ada. (Ahmadjayadi C, 2010). Sebagai calon pengguna cloud computing tentu ada beberapa hal yang harus kita ketahui seperti siapa yang berada di cloud itu, siapa yang mengelola (partisipant) cloud itu, siapa yang bertanggung jawab masalah liability, bagaimana aturan main di dalam cloud yang melibatkan beberap pihak, bagaimana mengelola database dan informasinya. Secara spesifik kita tentu harus tau bagaimana penerapan keamanan database dan informasi dari berbagai ancaman yang ada dan yang terpenting kita perlu pembuktian dalam hal keamanan data kita. Agar aman di Cloud, perusahaan harus benar-benar yakin bahwa penyedia jasa tidak hanya menjanjikan keamanan, tetapi juga harus membuktikannya. (Prof. Richardus Eko Indrajit ,IDSIRTII).

\section{KESIMPULAN}

Berdasarkan konsep, aplikasi, dampak yang ditimbulkan, dan kendala kendala dalam pengembangan cloud computing, maka perlu menganalisis berbagai kemungkinan mengenai perkembangan cloud computing ke depannya. Secara umum, dengan melihat berbagai manfaat dan resiko yang diperoleh user dalam menggunakan cloud computing, maka ada pandangan bahwa cloud computing akan semakin luas digunakan. Pengembangan cloud computing ini terutama akan mengarah pada prinsip survivaldan opportunity and need, yang artinya teknologi ini akan berkembang dan berusaha survive dengan cara mengadaptasi kebutuhan sosial, politik, dan ekonomi dari user itu sendiri. Oleh karena itu, pengambangan cloud computing akan mengarah pada berkembangnya suatu teknologi pengiring cloud computing ini yaitu suatu bentuk teknologi yang dapat menjamin keamanan data. Selain itu, perkembangan cloud computing ini selanjutnya akan memasuki tahap integrasi antar berbagai provider dengan mengedepankan prinsip interoperabilitas.

Adanya perkembangan secara teknis tersebut menyebabkan bertambahnya tingkat kepercayaan tinggi dari pengguna sehingga pada akhirnya model komputasi ini akan mendominasi penggunaan di level korporasi. penerapan teknologi cloud computing di Indonesia belum berjalan mapan karena banyaknya kendala dan dilema-dilema yang muncul dari implementasi cloud computing. Teknologi cloud computing akan mengalami perkembangan sesuai prinsip survival dan needs and oportunities, yang berupa intergrasi antar sistem operasi yang berbeda dan 
penciptaan teknologi yang menjamin keamanan data, serta pengapliaksian teknolgi cloud computing dalam perangkat mobile communication. Perkembangan ini bersifat bertahap atau sesuai dengan prinsip metamorphosis, agar user dapat beradaptasi.

Kedepannya, cloud computing akan semakin luas digunakan karena faktor tingginya kepercayaan terhadap teknologi dan faktor karakteristik teknologi cloud computing yang relatif murah dan memberikan banyak kemudahan khususnya di lembaga penelitian/ riset.

\section{DAFTAR PUSTAKA}

Mustikasari E., Implementasi Cloud Computing dalam Mendukung Riset di Lingkup Pusat Penelitian dan Pengembangan Sumberdaya Laut dan Pesisir, Kementerian Kelautan dan Perikanan, Prosiding e-Indonesia Initiatif (ell) Forum Ke VII, Konferensi dan Temu Nasional Teknologi Informasi dan Komunikasi (TIK) untuk Indonesia, Membangun Ekosistem Broadband dan Merancang Komputasi Awan Indonesia, 2011

http://www.alkode.net/2010/05/05/keamanan-isuutama-komputasi-awan/ diakses pada 16-112010: 01:24 WIB

Budiyanto, A., Pengantar Cloud Computing, 2012
Rahardjo. B, Materi Kuliah Keamanan Informasi Lanjut, 'Prinsip Keamanan',STEI MCIO -ITB, 2010.

http://uswahtech.uswah.net/berita-196-mengenalteknologi-cloud-computing.html diakses pada 2015- 2010: 08:31 WIB

http://www.tempointeraktif.com/hg/it/2009/08/25/ brk,20090825-194235,id.html diakses pada 21-12010: 08:31 WIB

http://www.detikinet.com/read/2010/02/24/084138/ 1305595/328/lebih-jauh-mengenal-komputasiawan diakses pada 22-15- 2010: 10:15 WIB

http://www.detikinet.com/read/2010/03/03/091126/ 1309948/328/lebih-jauh-mengenal-komputasiawan-2- diakses pada 23-15- 2010: 13:31 WIB

h t t p : / / w w w. w a e n a.org / index.php?option=com_content\&task=view\& id =4726\&ltemid=51 diakses pada 24-15- 2010: 11:31 WIB

Ahmadjayana C, Pointer Seminat Innovation Cloud Computing, ITB 2010).

http://debuh.com/berita-internet/cloud-computingancam-pekerja-ti-konvensional/10080 diakses pada 25-15- 2010: 13:21 WIB 